\title{
Gimatecan and other camptothecin derivatives poison Leishmania DNA-topoisomerase IB leading to a strong leishmanicidal effect
}

\author{
Christopher F. Prada ${ }^{a, 1}$, Raquel Álvarez-Velilla ${ }^{a, 1}$, Rafael Balaña-Fouce ${ }^{a, *}$, Carlos Prietob \\ Estefania Calvo-Álvarez ${ }^{\mathrm{a}, 1}$, Jose Miguel Escudero-Martínez ${ }^{\mathrm{a}, 1}$, José María Requena ${ }^{\mathrm{c}}$, \\ César Ordóñez $^{\mathrm{a}, 1}$, Alessandro Desideri ${ }^{\mathrm{d}}$, Yolanda Pérez-Pertejo ${ }^{\mathrm{a}, 1}$, Rosa M. Reguera ${ }^{\mathrm{a}, 1}$ \\ a Departamento de Ciencias Biomédicas, Universidad de León, Campus de Vegazana s/n, 24071 León, Spain \\ b Instituto de Biotecnología de León (INBIOTEC), Parque Científico de León, Avenida Real 1, 24006 León, Spain \\ 'Departamento de Bioquímica y Biología Molecular, Centro de Biología Molecular "Severo Ochoa" c/Nicolás Cabrera, 1, 28049 Madrid, Spain \\ d Department of Biology, University of Rome "Tor Vergata" Via della Ricerca Scientifica 1, 00133, Roma, Italy
}

\section{A R T I C L E I N F O}

\section{Article history:}

Received 14 December 2012

Accepted 22 February 2013

Available online xxx

\section{Keywords:}

DNA topoisomerase IB

Gimatecan

Camptothecin

Splenic explants

Leishmania spp.

\begin{abstract}
A B S T R A C T
The aim of this work is the in vitro and ex vivo assessment of the leishmanicidal activity of camptothecin and three analogues used in cancer therapy: topotecan (Hycantim ${ }^{\mathbb{R}}$ ), gimatecan (ST1481) and the prodrug irinotecan $\left(\right.$ Camptosar $^{\circledR}$ ) as well as its active metabolite SN-38 against Leishmania infantum. The activity of camptothecin and its derivatives was studied on extracellular L. infantum infrared-emitting promastigotes and on an ex vivo murine model of infected splenocytes with L. infantum fluorescent amastigotes. In situ formation of $\mathrm{SDS} / \mathrm{KCl}$ precipitable DNA-protein complexes in Leishmania promastigotes indicated that these drugs are DNA topoisomerase IB poisons. The inhibitory potency of camptothecin derivatives on recombinant $L$. infantum topoisomerase IB was assessed in vitro showing that gimatecan is the most active compound preventing the relaxation of supercoiled DNA at submicromolar concentrations. Cleavage equilibrium assays in Leishmania topoisomerase IB show that gimatecan changes the equilibrium towards cleavage at much lower concentrations than the other camptothecin derivatives and that this effect persists over time. Gimatecan and camptothecin were the most powerful compounds preventing cell growth of free-living L. infantum promastigotes within the same concentration range. All these compounds killed L. infantum splenocyte-infecting amastigotes within the nanomolar range. The amastigote form showed higher sensitivity to topoisomerase IB poisons (with high therapeutic selectivity indexes) than free-living promastigotes. All the compounds assayed poisoned $L$. infantum DNA topoisomerase IB leading to a strong leishmanicidal effect. Camptothecin derivatives are suitable for reducing the parasitic burden of ex vivo infected splenocytes. The selectivity index of gimatecan makes it a promising drug against this neglected disease.
\end{abstract}

(c) 2013 Elsevier Inc. All rights reserved.

\section{Introduction}

Visceral leishmaniasis in Europe is a disease caused by the protozoan pathogen Leishmania infantum that affects all countries of the Mediterranean region. The disease has a low prevalence in humans - the definitive host - but not in dogs, which act as reservoirs of the parasite. The risk of human disease significantly increased in immunosuppressed individuals mainly

\footnotetext{
Abbreviations: Top, DNA topoisomerases; TopIB, DNA topoisomerase IB; LdTopIB, L. donovani TopIB; LiTopIB, L. infantum TopIB; IFP1.4, infrared fluorescent protein 1.4; $\mathrm{SI}_{48 \mathrm{~h}}$, selectivity index at $48 \mathrm{~h}$; MDR-1, multidrug resistant protein 1 .

* Corresponding author. Tel.: +34 987 291257; fax: +34 987291252

E-mail address: rbalf@unileon.es (R. Balaña-Fouce).

1 Tel.: +34987 291257; fax: +34987 291252 .
}

linked to HIV, but due to highly active antiretroviral therapies its presence has dramatically decreased [1]. Current pharmacopoeia against leishmaniasis includes old-fashioned pentavalent antimonium derivatives, as well as amphotericin $\mathrm{B}$, paromomycin and alkylphospholipids [2]. Most of them have many undesirable side effects or require parental administration and longterm treatments, which can make treatment difficult to adhere to [3].

Searching for differentiable targets between the host and pathogen is a recognized strategy for designing new drugs. Type IB DNA topoisomerases (TopIB) were indicated as putative targets in proliferative processes when their mechanism of action was originally shown [4]. Since then, numerous compounds have shown antiproliferative effects: (i) by interfering with the catalytic properties of enzymes (TopIB inhibitors) or (ii) by stabilizing the

0006-2952/\$ - see front matter (c) 2013 Elsevier Inc. All rights reserved. http://dx.doi.org/10.1016/j.bcp.2013.02.024 
enzyme-DNA complex - a transient step of all Top activities - that can be hindered in time by many compounds (TopIB poisons). TopIB poisons prevent the religation step and produces single DNA breaks that interfere with the replication fork of the dividing cells [5]. An amazing result found in 2003 was that L. infantum TopIB (LiTopIB) was a heterodimeric enzyme encoded by two genes that were placed on different chromosomes [6]. This characteristic is only shared by certain phylogenetically close microorganisms such as Trypanosoma cruzi and T. brucei [7]. Despite these differences, most of the domains related to the enzymatic activity are conserved between both subunits, which are interconnected by two polypeptide extensions that play the role of a putative linker. This region is not needed for TopIB activity, but it contributes to DNA binding and camptothecin inhibition, theoretically by slowing down the religation step of the nicking-closing reaction [8-10].

Camptothecin and derivatives, known as TopIB poisons, develop their function by binding in a specific and reversible manner to the transient DNA-enzyme complexes [11]. These drugs effectively target the TopIB-DNA binary complex, while they do not bind to the enzyme alone and display a weak affinity for DNA in the absence of the enzyme [12]. The presence of cleavage complexes generates collisions with the replication fork, causing DNA breaks by converting transient complexes to permanent strand damage and consequently making these compounds powerful anticancer drugs. Camptothecin in fact shows a remarkable antiproliferative potential in vitro against a wide range of tumor cells in the submicromolar range $[13,14]$ and it has been the first compound described as a specific inhibitor of eukaryotic cell TopIB with no effect on the bacterial TopIA and a well-defined mechanism of action. The development of camptothecin derivatives against several types of cancer has resulted in two watersoluble compounds currently used in clinical practice: topotecan (Hycantim ${ }^{\mathbb{R}}$ ) and the pro-drug irinotecan (Camptosar ${ }^{\mathbb{R}}$ ). In addition a third compound, gimatecan (ST1481) is an orphan drug that is being studied in clinical phase II against astrocytoma, glioblastoma and oligodendroglial tumors [15].

TopIB is essential for DNA replication, recombination and repair mechanisms. Most organisms are unable to survive in the absence of this enzyme [16]. Previous works have unsuccessfully tried to create Leishmania [17] or T. brucei [18] strains lacking the small monomer or both protomers, respectively. For these reasons and because of distinct structural differences between human and leishmanial TopIB, this protein is considered a valuable target for chemotherapy [19].

This paper explains the effect of these camptothecin derivatives on an ex vivo murine model of infected splenocytes with L. infantum. Furthermore, the in vitro effect of these compounds reveals for the first time their ability to trap TopIB-DNA covalent complexes on Leishmania parasites, thus preventing the religation step at micromolar concentrations.

\section{Materials and methods}

\subsection{Reagents and culture media}

Pyrococcus furiosus (Pfu), klenow polymerases and restriction enzymes were acquired from Roche (Roche Farma SA, Spain) and GE Healthcare (Spain). T4 DNA ligase was obtained from Stratagene (La Jolla, CA, USA). Cell culture media, camptothecin, irinotecan and SN-38 were purchased from Sigma (Sigma-Aldrich, Spain). Topotecan (Hycantim ${ }^{\mathbb{R}}$ ) was obtained from GlaxoSmithKline (UK). Gimatecan and camptothecin-N-oxide were kind gifts of Sigma Tau to Alessandro Desideri. Primers for PCR amplification were from Sigma Genosys (UK).

\subsection{Biological material}

L. infantum-IFP1.4 promastigotes and infecting amastigotes were obtained by stable transfection of $L$. infantum (BCN-150 strain) with the pLEXSY-IFP1.4 vector [20]. This vector contains the 987 bp ORF region of the infrared fluorescent protein 1.4 (IFP1.4) derived from Discosoma sp., [21] kindly provided by Dr. Roger Y. Tsien (Department of Pharmacology; Department of Chemistry and Biochemistry, University of California, San Diego, USA).

To obtain naturally amastigote-infected splenocytes cultures, $\mathrm{BALB} / \mathrm{c}$ mice were inoculated intraperitoneally with $10^{8} \mathrm{~L}$. infantum-IFP1.4 purified metacyclic promastigotes [22]. Five weeks post-infection spleens were aseptically dissected and infected splenocytes were cultured as described previously [20]. Different concentrations of miltefosine (included as positive control) and camptothecin derivatives were administered to the explants for $48 \mathrm{~h}$. The viability of infecting amastigotes was assessed registering the fluorescence emission at $708 \mathrm{~nm}$ in an Odyssey (Li-Cor) infrared imaging system. To determine the cytotoxicity of the drugs in mammalian cells, the Alamar Blue staining method was used on drug-exposed splenocytes derived from uninfected mice, according to manufacturer's recommendations. The animal research described in this manuscript complied with Spanish (Ley 32/2007) and European Union Legislation (2010/ $63 / \mathrm{UE}$ ). The used protocols were approved by the Animal Care Committee of Universidad de León (Spain).

\subsection{DNA relaxation assays}

Cloning of LiTopIB ORFs (encoding large and small subunits), expression and purification of the enzyme were carried out as previously described [9]. TopIB activity was assayed by the relaxation of negatively supercoiled plasmid DNA. The reaction mixture, in a total volume of $20 \mu \mathrm{L}$, contained $0.5 \mu \mathrm{g}$ of supercoiled DNA from the pBluescript SK(-) phagemid (pSK), $10 \mathrm{mM}$ Tris- $\mathrm{HCl}$ buffer $\mathrm{pH} 7.5,5 \mathrm{mM} \mathrm{MgCl}_{2}, 0.1 \mathrm{mM}$ EDTA, $15 \mu \mathrm{g} / \mathrm{mL}$ bovine serum albumin, $50 \mathrm{mM} \mathrm{KCl}, 1$ unit of the leishmanial enzyme and $1 \mu \mathrm{L}$ of the tested drugs at different concentrations (dose dependent) or at a fixed drug concentration $(75 \mu \mathrm{M})$ at different time points ranging from 0.2 to $15 \mathrm{~min}$ (time-course). Reaction mixtures were incubated at $37^{\circ} \mathrm{C}$. Enzyme reactions were stopped by the addition of up to $1 \% \operatorname{SDS}(\mathrm{w} / \mathrm{v}$ ) (final concentration) and digested with $1 \mathrm{mg} / \mathrm{mL}$ proteinase $\mathrm{K}$ at $37^{\circ} \mathrm{C}$ during one extra hour to remove protein that remained attached to the DNA fragments. The extent of plasmid DNA relaxation was assessed in $1 \%$ agarose gels by electrophoresis in $0.1 \mathrm{M}$ Tris borate EDTA buffer $(\mathrm{pH} 8.0)$ at $2 \mathrm{~V} / \mathrm{cm}$ for $16 \mathrm{~h}$. Gels were visualized with UV illumination after staining with ethidium bromide $(0.5 \mu \mathrm{g} / \mathrm{mL})$. A further electrophoresis was run in the presence of $0.1 \mu \mathrm{g} / \mathrm{mL}$ ethidium bromide, in order to separate the nicked DNA from the relaxed topoisomers.

\subsection{Oligonucleotide assays}

A 202-bp PvuII/HindIII fragment of pSK DNA substrate $\left[{ }^{32} \mathrm{P}\right]-$ labeled at a single $3^{\prime}$-end, was prepared as described elsewhere [23]. Equal concentrations of LiTopIB were incubated with at least $1.5 \mu \mathrm{L}$ of DNA containing a minimum of $100,000 \mathrm{cpm}$ in $10 \mathrm{mM}$ Tris- $\mathrm{HCl}$ buffer $\mathrm{pH} 7.5,5 \mathrm{mM} \mathrm{MgCl}_{2}, 5 \mathrm{mM}$ DTT, $0.1 \mathrm{mM}$ EDTA, $15 \mu \mathrm{g} / \mathrm{mL}$ bovine serum albumin, $50 \mathrm{mM} \mathrm{KCl}$, and different concentrations of camptothecin, topotecan, SN-38, gimatecan and camptothecin-N-oxide in 1\% DMSO. Following incubation for $2 \mathrm{~min}$ at room temperature, reactions were either stopped directly with $1 \%$ SDS or treated with $0.5 \mathrm{M} \mathrm{NaCl}$ for $1 \mathrm{~h}$ at $25{ }^{\circ} \mathrm{C}$ to force LiTopIB religation and then stopped with $0.5 \%$ SDS at indicated times. The samples were heated at $75{ }^{\circ} \mathrm{C}$ for an extra 
15-min period, treated with proteinase $\mathrm{K}$ and subjected to doubleethanol precipitation prior to electrophoresis in a $16 \%$ polyacrylamide/7 M urea gel. Stabilized cleavage products were visualized with a PhosphorImager (Molecular Dynamics, Sunnyvale, CA).

\subsection{In situ sensitivity to camptothecin derivatives}

For drug-induced protein-DNA complex determination, L. infantum promastigotes, previously labeled for $24 \mathrm{~h}$ with $0.5 \mu \mathrm{Ci} / \mathrm{mL}\left[2-{ }^{14} \mathrm{C}\right]$ thymidine, were exposed to different concentrations of camptothecin and its derivatives for $30 \mathrm{~min}$, followed $\mathrm{SDS} / \mathrm{KCl}$ method as previously described [20]. All assays included solvent controls. DNA fragments formation, as a percentage of total labeled DNA, was calculated as follows: $[(\mathrm{dpm}$ in $\mathrm{SDS} / \mathrm{KCl}$ drug $-\mathrm{dpm}$ in SDS/KCl solvent)/(dpm total incorporation $)] \times 100$. Each experiment was run at least in triplicate. For each drug the concentration causing $50 \%$ of DNA to be cleaved $\left(\mathrm{CC}_{50}\right)$ was calculated from dose/response curves.

\section{Results}

\subsection{Leishmanicidal effect of camptothecin and analogues}

We have analyzed the effect of the specific TopIB inhibitors outlined in Fig. 1 on the proliferation rate of $L$. infantum-IFR1.4 promastigotes and amastigotes. Table 1 shows the $\mathrm{IC}_{50}$ values obtained from dose-response plots, based on the percentage of infrared fluorescence signal at $708 \mathrm{~nm}$, obtained for free-living promastigotes and amastigote-infected splenocytes, exposed for $48 \mathrm{~h}$ to several concentrations of the tested compounds in comparison to untreated controls. The $\mathrm{IC}_{50}$ value obtained with miltefosine (a leishmanicidal alkylphospholipid) is also reported in Table as positive control. No differences in drug sensitivities are found between the IFR1.4-transfected strain and the wild-type (data not shown). Gimatecan and camptothecin are the most powerful compounds in killing promastigotes with $\mathrm{IC}_{50}$ values near $1 \mu \mathrm{M}$. The water-soluble derivative topotecan and SN-38 are less effective, but both have $\mathrm{IC}_{50}$ values lower than the positive-control miltefosine, that is more effective than camptothecin- $\mathrm{N}$-oxide and irinotecan. The table also shows the $\mathrm{IC}_{50}$ value obtained for the amastigote-infected splenocytes. Gimatecan is the most effective one, having $\mathrm{IC}_{50}$ value on the nanomolar range, followed by camptothecin, SN-38 and topotecan. Camptothecin-N-oxide and miltefosine are the weakest compounds in killing amastigotes working in the lower micromolar range. Irinotecan does not show a significative leishmanicidal effect likely due to its pro-drug nature.

The leishmanicidal effect of these compounds has been validated checking their potential toxicity on mammalian cells. For this purpose, freshly isolated splenocytes, from uninfected BALB/c mice, have been exposed to different drug concentrations for $48 \mathrm{~h}$ and the percentage of living cells has been fluorimetrically determined with the Alamar Blue staining technique. The selective

A

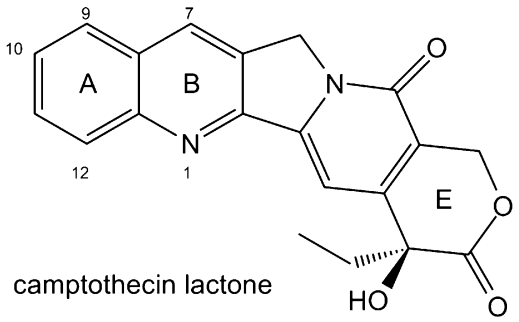<smiles>CCCCCCCCOc1ccccc1</smiles>

B<smiles>Cc1cc2c(CN(C)C)cccc2nc1C</smiles><smiles>CC1=Nc2ccccc2/C1=C/N=CC(C)(C)C</smiles>

topotecan

gimatecan<smiles></smiles>

camptothecin $\mathrm{N}$-oxide

C

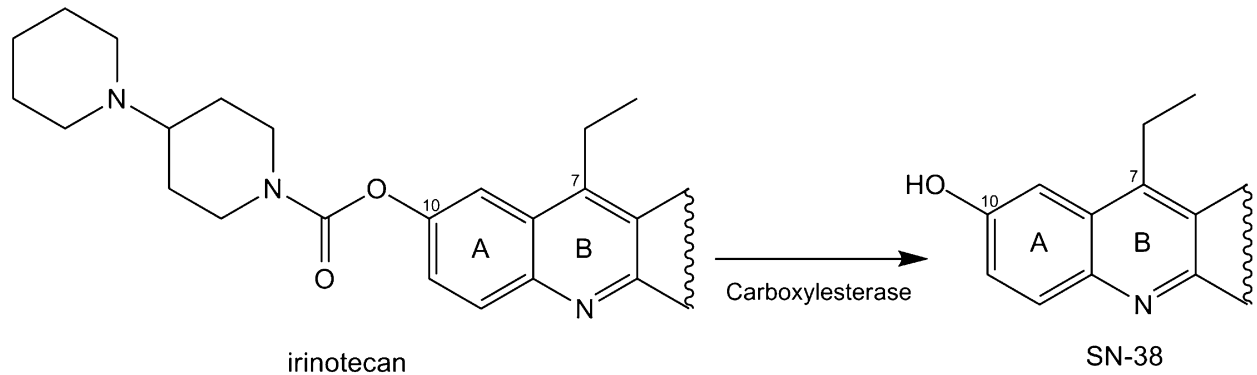

Fig. 1. Chemical structures of the camptothecin derivatives used in the study. (A) Lactone/carboxylate equilibrium of the camptothecin E-ring; (B) different moieties substituting the A and B rings of topotecan, gimatecan and camptothecin-N-oxide; (C) enzymatic hydrolysis of the prodrug irinotecan to the active compound SN-38. 
Table 1

IC $_{50}$ calculation after a 48 -h period of exposure to the selected compounds of $L$. infantum promastigotes, ex vivo infected splenocytes and uninfected splenocytes. ${ }^{\text {a }}$

\begin{tabular}{|c|c|c|c|c|}
\hline \multirow[t]{2}{*}{ Drug } & \multicolumn{4}{|l|}{$\mathrm{IC}_{50}$ for $^{\mathrm{b}}:$} \\
\hline & L. infantum promastigotes $(\mu \mathrm{M})^{\mathrm{c}}$ & Infecting amastigotes $(\mu \mathrm{M})^{\mathrm{c}}$ & Uninfected splenocyte culture $(\mu \mathrm{M})^{\mathrm{d}}$ & $\overline{\mathrm{SI}_{48}{ }^{\mathrm{e}}}$ \\
\hline Miltefosine & $25.15 \pm 2.35$ & $8.7 \pm 0.07$ & $504.1 \pm 7.0$ & 57.9 \\
\hline Camptothecin & $1.12 \pm 0.13$ & $0.03 \pm 0.01$ & $0.62 \pm 0.13$ & 20.7 \\
\hline Topotecan & $10.86 \pm 1.64$ & $0.16 \pm 0.05$ & $4.96 \pm 0.95$ & 31.0 \\
\hline Gimatecan & $1.73 \pm 0.10$ & $0.001 \pm 0.000$ & $0.21 \pm 0.00$ & 175 \\
\hline Camptothecin-N-oxide & $90.02 \pm 1.20$ & $1.48 \pm 0.54$ & $3.95 \pm 1.55$ & 2.7 \\
\hline $\mathrm{SN}-38$ & $12.20 \pm 2.11$ & $0.05 \pm 0.03$ & $0.54 \pm 0.08$ & 9.8 \\
\hline Irinotecan & $>200$ & $>100$ & $>200$ & ND \\
\hline
\end{tabular}

$\mathrm{ND}=$ no determined.

${ }^{\text {a }} \mathrm{IC}_{50}$ at $48 \mathrm{~h}$ of the compounds in freshly uninfected splenocyte culture and $\mathrm{SI}_{48 \mathrm{~h}}$ values between this cell line and infected splenocytes with $L$. infantum amastigotes ex vivo

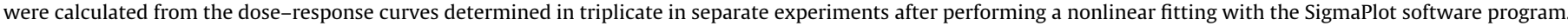

b Mean \pm SD.

c The viability of both L. infantum IFP1.4-promastigotes and infecting IFP1.4-amastigotes was assessed registering their infrared-fluorescence emission at 708 nm in an Odyssey (Li-Cor).

d The viability of uninfected splenocyte culture was assessed by using the Alamar Blue staining method on drug-exposed splenocytes derived from uninfected mice.

e Selectivity index; $\mathrm{SI}_{48 \mathrm{~h}}$, $\mathrm{IC}_{50}$ for uninfected splenocyte culture $/ \mathrm{IC}_{50}$ for amastigotes.

index $\left(\mathrm{SI}_{48 \mathrm{~h}}\right)$, calculated as the $\mathrm{IC}_{50}$ ratio of the uninfected and $L$. infantum-IFR1.4 infected splenocytes, reported in Table 1, shows that gimatecan is the safest compound with a $\mathrm{SI}_{48 \mathrm{~h}}$ value three fold higher than miltefosine and significantly higher than the other tested compounds.

\subsection{In situ formation of cleavable complexes}

The formation of enzyme-DNA adducts, in promastigotes exposed to camptothecin analogues, has been evaluated by protein precipitation with SDS. L. infantum promastigotes, grown in the presence of $\left[2-{ }^{14} \mathrm{C}\right]$-thymidine, have been exposed to increasing drugs concentrations over a period of $30 \mathrm{~min}$. The percentage of labeled $\mathrm{SDS} / \mathrm{KCl}$ precipitable complexes with respect to total labeled DNA has been determined using camptothecin as reference drug (Fig. 2A). Gimatecan displays the maximum DNA-cleaving potency $\left(\mathrm{CC}_{50}=0.02 \mu \mathrm{M}\right)$ since a gimatecan concentration of
$0.3 \mu \mathrm{M}$ is enough to obtain $80 \%$ of cleaved DNA (Fig. $2 \mathrm{C}$ ). A camptothecin or topotecan concentration of 1 and $10 \mu \mathrm{M}$ respectively is needed to obtain a comparable DNA breakage percentage (Fig. 2A and B). Camptothecin-N-oxide reaches the same percentage at a concentration of $90 \mu \mathrm{M}$ (Fig. 2D), whilst in the case of SN-38 the maximum concentration of cleaved DNA is $50 \%$ even at a concentration of $90 \mu \mathrm{M}$ (Fig. 2E).

\subsection{LiTopIB inhibition by camptothecin and derivatives}

The effect of the different compounds on the relaxation activity of LiTopIB has been monitored over time incubating $1 \mathrm{U}$ of LiTopIB with $75 \mu \mathrm{M}$ of each derivative in the presence of $0.5 \mu \mathrm{g}$ of $37^{\circ} \mathrm{C}$ pre-warmed supercoiled pSK DNA. Aliquots have been then taken at different time points, ranging from 0.2 to $15 \mathrm{~min}$. As shown in Fig. 3A, in absence of the drug, the supercoiled substrate is fully processed after 0.2 min. Camptothecin and SN-38 inhibit the
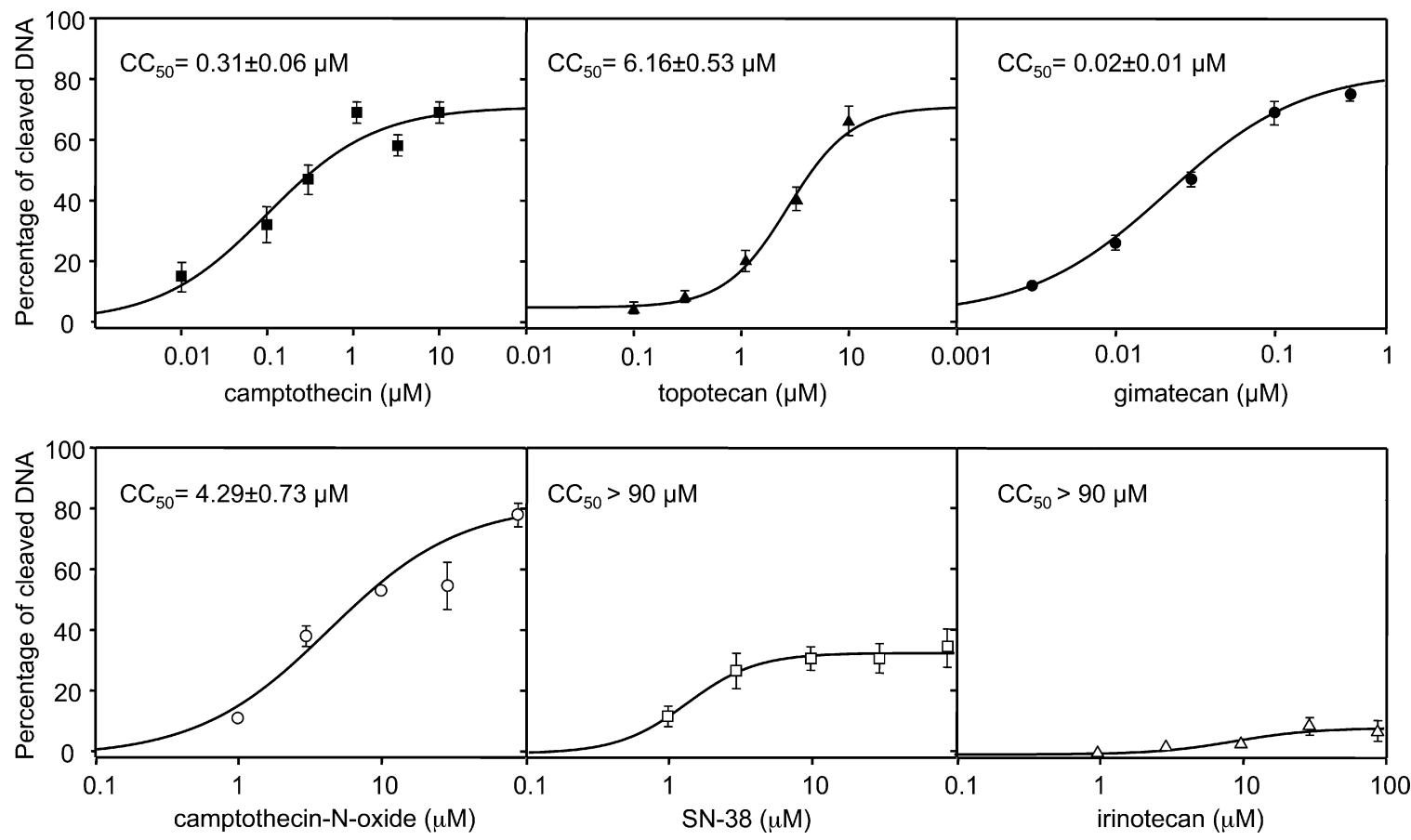

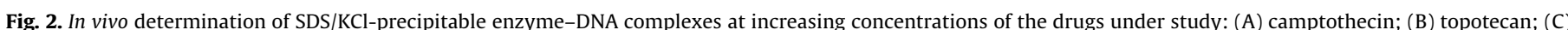

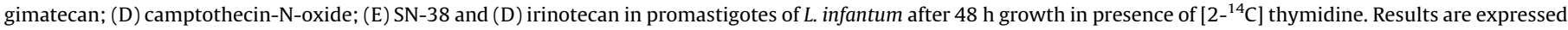
as mean \pm SE of at least three different experiments by duplicate. 
A
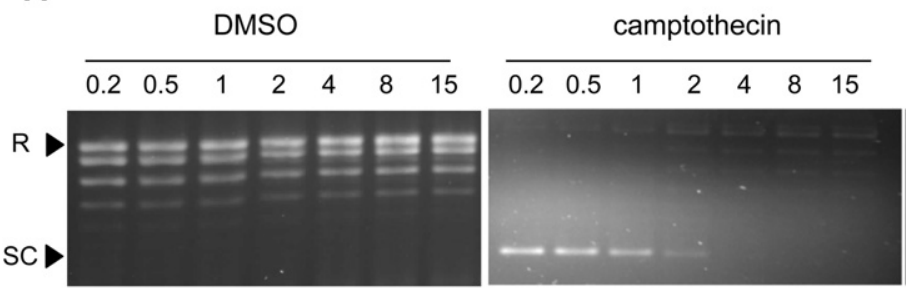

camptothecin- $\mathrm{N}$-oxide
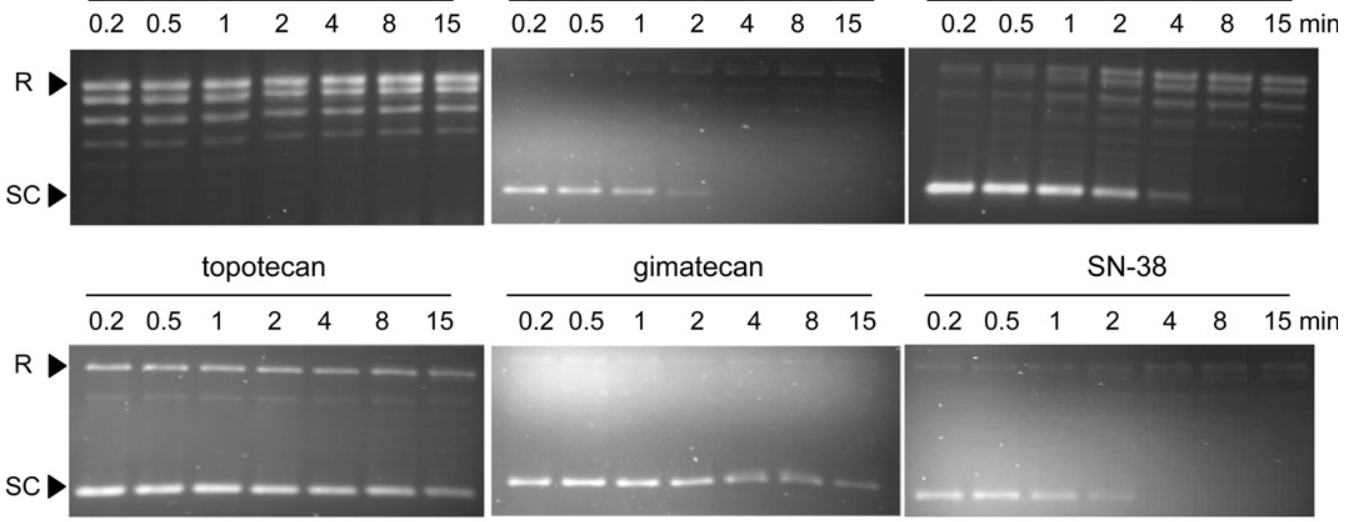

B

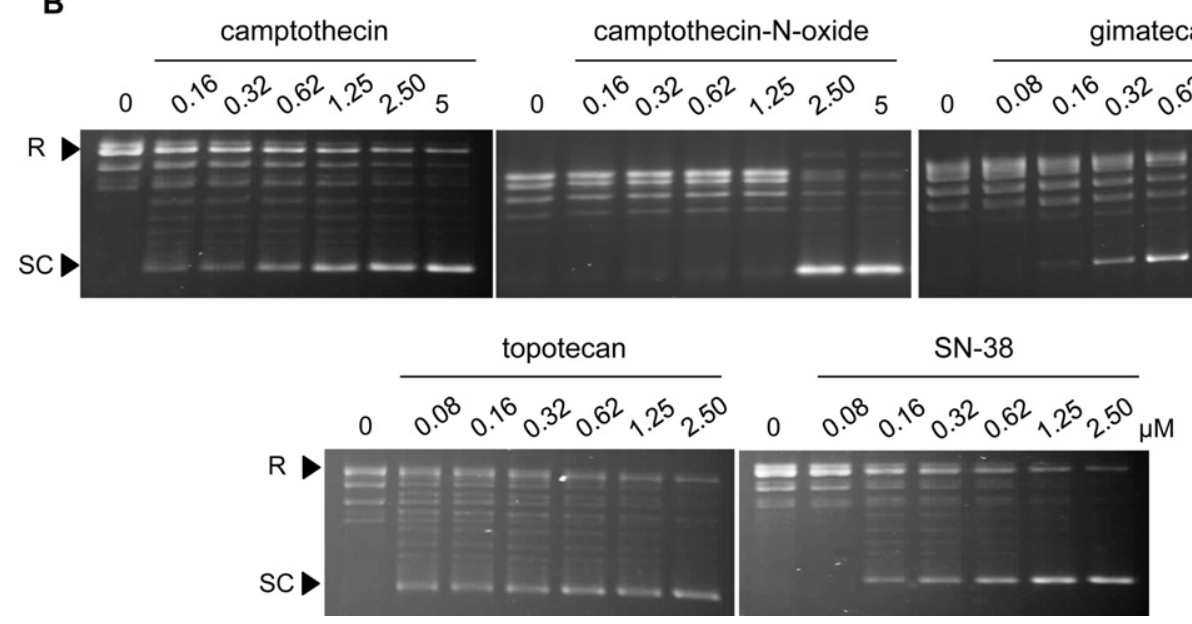

Fig. 3. Inhibition of LiTopIB-mediated DNA relaxation by camptothecin analogues (A) time-course inhibition of LiTopIB relaxation activity mediated by camptothecin analogues at a fixed $75 \mu \mathrm{M}$ concentration; (B) dose-dependent LiTopIB relaxation activity inhibition at the optimum time-point determined in A panel. Key: $\mathrm{R}=$ relaxed DNA; $\mathrm{SC}=$ supercoiled DNA. Reactions were incubated at $37^{\circ} \mathrm{C}$ in a final concentration of $150 \mathrm{mM} \mathrm{KCl}$ and then stopped with SDS up to a final concentration of $1 \%$ of reaction volume. Products were resolved in a $1 \%$ agarose gel and visualized by ethidium bromide staining. The results are representative of three independent trials.

relaxation of supercoiled DNA up to $2 \mathrm{~min}$, camptothecin-N-oxide up to $4 \mathrm{~min}$, whilst gimatecan or topotecan are the most efficient ones preventing the relaxation activity of the enzyme up to $15 \mathrm{~min}$.

The inhibitory potency of the camptothecin derivatives on the relaxation activity of recombinant LiTopIB was also assessed after $30 \mathrm{sec}$ as a function of drug concentrations (Fig. 3B). Topotecan, camptothecin, gimatecan and SN38 have a comparable efficacy whilst larger camptothecin- $\mathrm{N}$-oxide concentrations are required to have the same level of inhibition (Fig. 3B).

\subsection{Camptothecin derivatives poison LiTopIB}

A cleavage-religation equilibrium assay has been carried out in order to assess the cleavage stabilization nature of these drugs as TopIB poisons. These compounds are expected to act stabilizing the cleavable complexes generated by the nicking action of the enzyme. Once the enzyme is attached to DNA and cuts one of its strands, camptothecin stabilizes the LiTopIB-DNA complex and hinders the religation of the nicked DNA [10]. A PvuII/HindIII fragment of pSK DNA has been incubated with $100 \mathrm{U}$ of LiTopIB in presence of different drugs concentrations $(0.1,1,10$ and $100 \mu \mathrm{M})$. The first lane of Fig. 4 shows that in absence of the drugs no signals of the cleaved oligo are observed, indicating that the religated/ uncleaved $(\mathrm{R} / \mathrm{U})$ equilibrium is shifted towards religation. In presence of $\mathrm{SN}-38$, topotecan and gimatecan the equilibrium is shifted towards cleavage, since several cleaved bands (CL1, CL2 and CL3) are appearing due to the stabilization of the cleavable complexes. Gimatecan is the most powerful compound, since it stabilizes the enzyme-DNA complexes at concentrations of $0.1 \mu \mathrm{M}$. Camptothecin and SN-38 require a concentration 10 -fold higher, whereas topotecan a 100 -fold higher concentration to reproduce comparable effects. It is interesting to notice that topotecan is not able to trap the CL2 cleavable complex, likely due to a low residence time of the drug in this site or to a different cleavage pattern for topotecan in which CL2 is not a preferred site [24].

Fig. 5 shows a cleavage complex reversal assay comparing the stability of both LiTopIB-camptothecin-DNA and LiTopIB-gimatecan-DNA ternary complexes. The reversal of the LiTopIB cleavable complexes is much slower for gimatecan than for camptothecin. The effect of camptothecin persists for two minutes, whilst the gimatecan-stabilized complex can be detected up to $15 \mathrm{~min}$. The long persistence time of gimatecan on the DNA cleaved site provides an explanation to its greater potency in inducing cell death. 
C.F. Prada et al./Biochemical Pharmacology $x x x(2013) x x x-x x x$

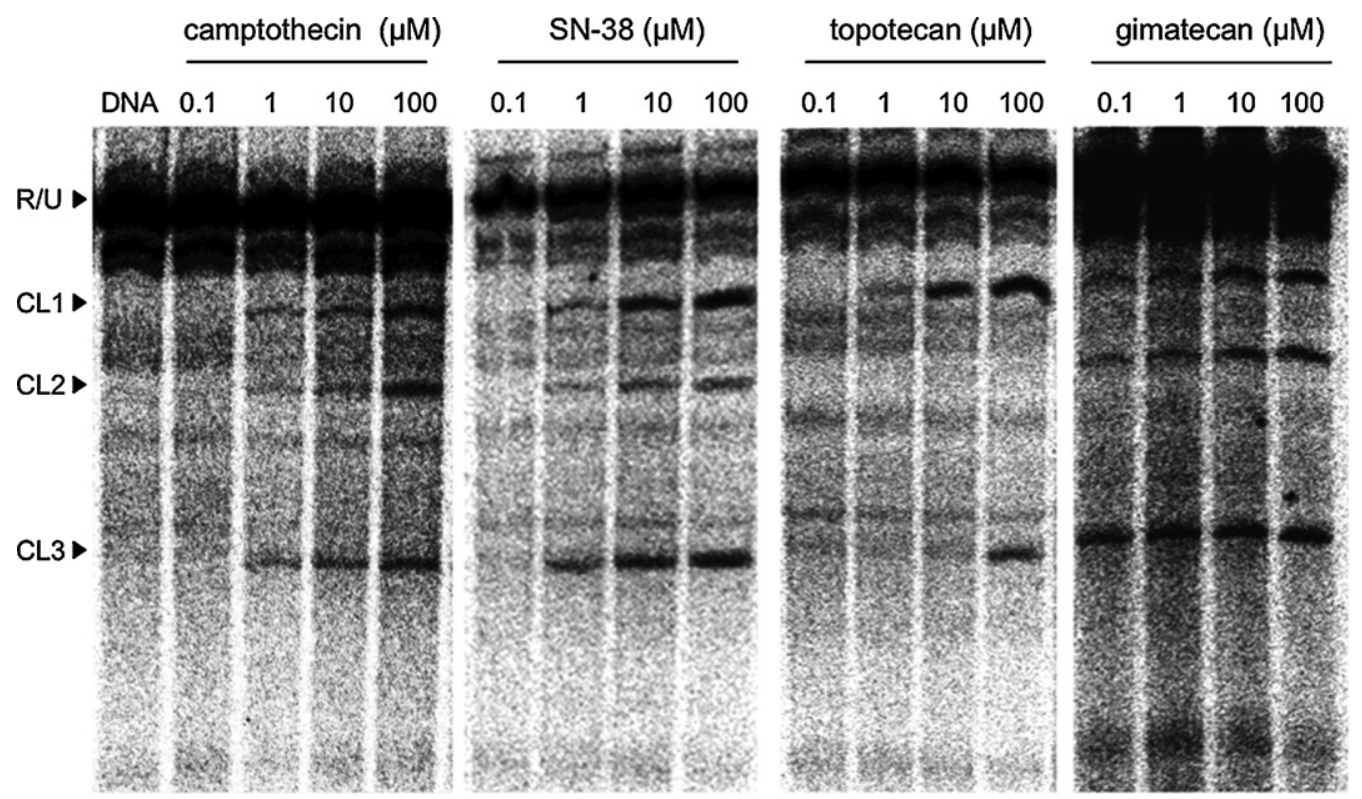

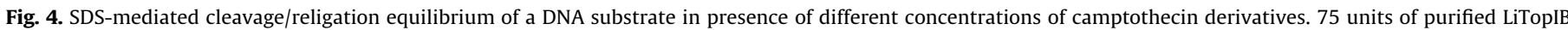

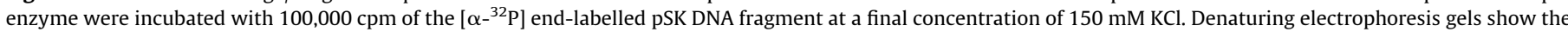

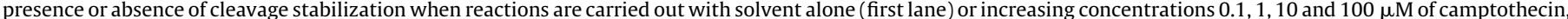

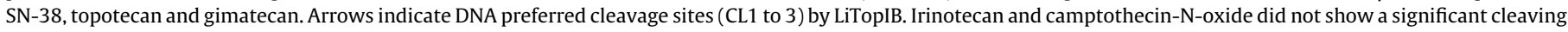
pattern at any concentration tested. The results are representative of three independent trials.

\section{Discussion}

One of the most problematic aspects of leishmaniases is the fast emergence of resistant strains against conventional drugs, which hinders the treatment and consequently, constant development of new therapeutic resources is required. In the present study, we have shown that gimatecan is a powerful growth inhibitor of L. infantum promastigotes that is even more lethal for its

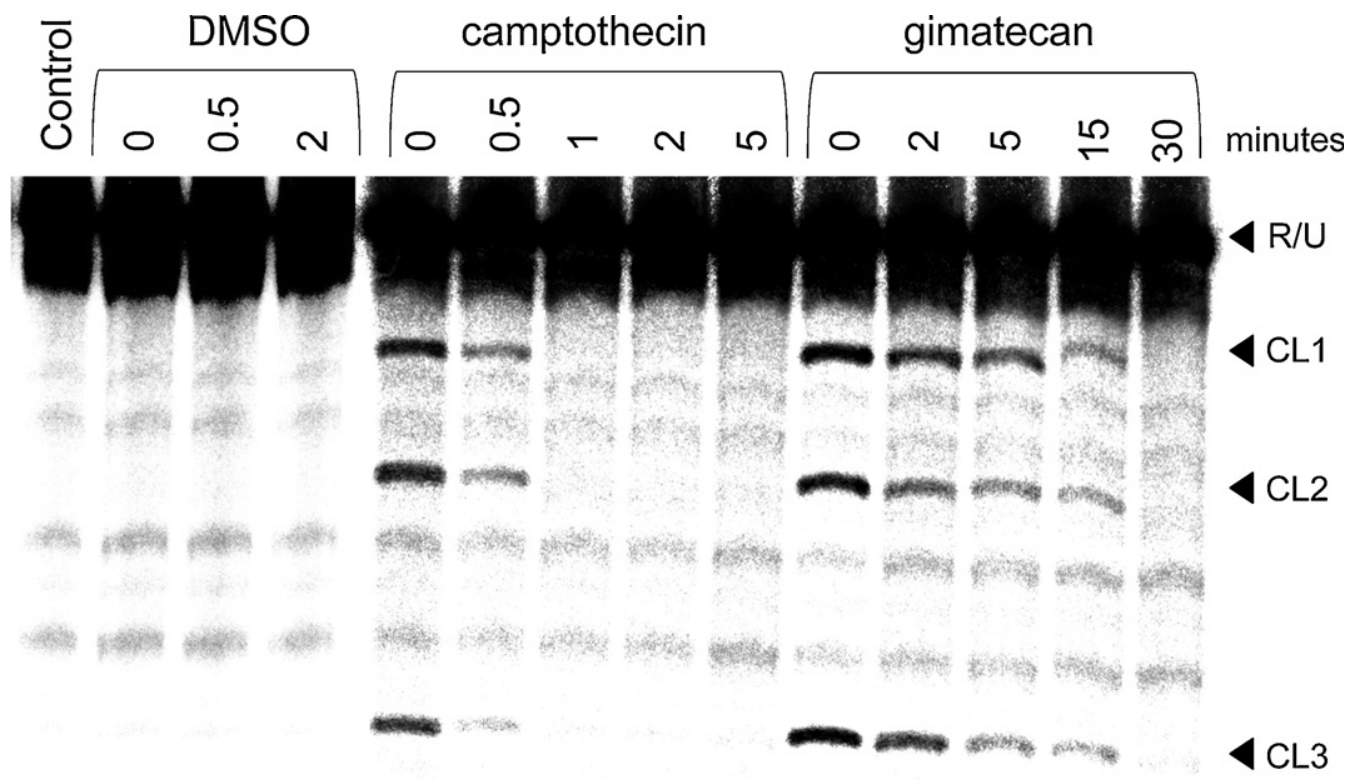

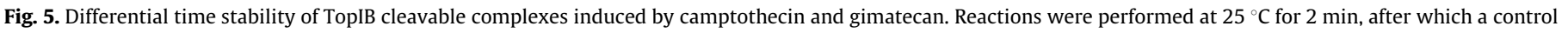
was taken (time 0 ) and $0.35 \mathrm{M} \mathrm{NaCl}$ was added. Times above each lane, aliquots were taken after $\mathrm{NaCl}$ addition and stopped by adding $0.5 \%$ SDS.

Please cite this article in press as: Prada CF, et al. Gimatecan and other camptothecin derivatives poison Leishmania DNA-topoisomerase IB leading to a strong leishmanicidal effect. Biochem Pharmacol (2013), http://dx.doi.org/10.1016/j.bcp.2013.02.024 
intracellular form (amastigote) (Table 1). In addition, gimatecan is also shown to be a potent LiTopIB-poison.

In vitro results show that the relaxation activity of $L$. infantum DNA topoisomerase IB is inhibited by all the camptothecin derivatives, with the exception of camptothecin- $\mathrm{N}$-oxide and irinotecan, within the nanomolar range (Fig. 2B), suggesting that this enzyme is the potential target in camptothecin-treated Leishmania parasites. Gimatecan stabilizes the cleavable complexes at a concentration 10-fold lower than camptothecin, and of any other camptothecin derivatives (Fig. 4). Moreover the gimatecan-stabilized complexes are slowly reverted in comparison with the ones stabilized by camptothecin (Fig. 5). This fact may explain the enhanced leishmanicidal effect of gimatecan, since drug-induced DNA damage is directly proportional to the lifespan of the ternary complex. The slow reversal of the gimatecan-induced cleavable complexes is likely due to its 7-t-butoxyiminomethyl substitution, since this position has been shown to be important in other 7-modified camptothecin derivatives [25]. The long residence time of the gimatecan stabilized ternary complexes, is also in agreement with the long time that the LiTopIB relaxation activity remains hindered by this drug (Fig. 3A) and the greater potency of gimatecan in inducing SDS/KCl-precipitable DNA-topoisomerase complexes in vivo (Fig. 2).

The leishmanicidal activity of the camptothecin derivatives has been validated on a model of mouse splenocytes infected with a $L$. infantum strain expressing IFP1.4, which permits to study the compounds under conditions that resemble those found in the animal, including the presence of the complete range of immune host cells, infected macrophages and fibroblasts [20]. For all the studied derivatives the sensitivity of the amastigote form is much higher than that of free-living promastigotes (Table 1). This is not an unexpected result since many drugs with different intracellular targets have similar behavior [26]. However, irinotecan does not have leishmanicidal effect (up to $100 \mu \mathrm{M}$ ) in the splenocytes, suggesting that this compound is not metabolically hydrolyzed to $\mathrm{SN}-38$ within the splenic explants.

A remarkable finding is the extraordinary power of gimatecan in all trials conducted both in vitro and ex vivo. This drug has a therapeutic selectivity index above 170 , three times higher than miltefosine that is clinically used for the treatment of leishmaniasis (Table 1). Furthermore, gimatecan presents a series of added values, which must be taken into consideration, as they substantially improve the therapeutic index obtained for this drug and make it interesting for the treatment of visceral leishmaniasis: (i) after oral administration the highest tissue levels are found in liver and spleen [27]; (ii) the percentage of active lactone form in plasma is 80 to $100 \%$, much higher than those of its analogues, topotecan, irinotecan and SN-38 estimated at ca. 20\% for each [28,29]; (iii) a half-life of over $76.5 \mathrm{~h}$, maintaining significant concentrations in plasma 7 days after the dose was given [28]; (iv) Zhu et al. [28] have shown in cancer patients that after weekly administration of oral gimatecan at $1.2 \mathrm{mg} / \mathrm{kg}$ concentration for 3 weeks the gimatecan is tolerated and has favorable pharmacokinetic properties. Miltefosine, despite its drug safety, has a less desirable dosage regimen that involves the administration of $1.76 \mathrm{mg} / \mathrm{kg} / \mathrm{d}$ for 28 days for an effective oral treatment of this cutaneous disease, resulting in difficulty of adherence to treatment of infected people in developing countries [30]; (v) unlike other camptothecins the pharmacokinetics of the compound appears to be more favorable in humans than in mice [29]; ( vi) it has recently been shown that gimatecan is not affected by multidrug resistant protein 1 (MDR-1) efflux in tumor cell lines (responsible for resistance to camptothecin), which have an orthologous protein-coding gene in Leishmania [15].
In conclusion, the present study indicates that all the here studied camptothecins with the exception of camptothecin-N-oxide, are Leishmania topoisomerase IB poisons in the low micromolar range, although gimatecan is the most efficient one and its excellent selectivity index suggest that this compound may be exploited as a potential drug candidate against visceral leishmaniasis.

\section{Conflict of interest statement}

The authors declare that there are no conflicts of interest.

\section{Acknowledgements}

This research was supported by Ministerio de Ciencia y Tecnología (grants AGL2009-11935/GAN and AGL2010-16078/ GAN), Instituto de Salud Carlos III (grants PI09/0448, PI12/00104 and the Network of Tropical Diseases RICET) and Junta de Castilla y León (grant Gr238) and AIRC (grant no. 10121). RAV, CFP and ECA are pre-doctoral fellows granted by Instituto de Salud Carlos III, JCyL-ESF and University of León, respectively. CP was supported by a Juan de la Cierva programme (JCI-2009-05444) of the Ministry of Economy and Competence (Spain). Authors wish to thank to Sigma-tau (Italy) for providing the gimatecan used in this study.

\section{References}

[1] Cruz I, Nieto J, Moreno J, Cañavate C, Desjeux P, Alvar J. Leishmania/HIV co-infections in the second decade. Indian J Med Res 2006;123:357-88.

[2] Berman J. Clinical status of agents being developed for leishmaniasis. Expert Opin Investig Drugs 2005;14:1337-46.

[3] Croft SL, Olliaro P. Leishmaniasis chemotherapy - challenges and opportunities. Clin Microbiol Infect 2011;17:1478-83.

[4] Champoux JJ. DNA topoisomerases: structure, function, and mechanism. Annu Rev Biochem 2001;70:369-413.

[5] Pommier Y. Topoisomerase I inhibitors: camptothecins and beyond. Nat Rev Cancer 2006;6:789-802.

[6] Villa H, Otero-Marcos AR, Reguera RM, Balaña-Fouce R, García-Estrada C, Pérez-Pertejo Y, et al. A novel active DNA topoisomerase I in Leishmania donovani. J Biol Chem 2003;278:3521-6.

[7] Bodley AL, Chakraborty AK, Xie S, Burri C, Shapiro TA. An unusual type IB topoisomerase from African trypanosomes. Proc Natl Acad Sci USA 2003;100:7539-44.

[8] Balaña-Fouce R, Redondo CM, Pérez-Pertejo Y, Díaz-González R, Reguera RM. Targeting atypical trypanosomatid DNA topoisomerase I. Drug Discov Today 2006;11:733-40.

[9] Díaz-González R, Pérez-Pertejo Y, Ordóñez D, Balaña-Fouce R, Reguera RM. Deletion study of DNA topoisomerase IB from Leishmania donovani: searching for a minimal functional heterodimer. PLoS ONE 2007;2:e1177.

[10] Prada CF, Alvarez-Velilla R, Diaz-González R, Prieto C, Pérez-Pertejo Y, BalañaFouce $R$, et al. A pentapeptide signature motif plays a pivotal role in Leishmania DNA topoisomerase IB activity and camptothecin sensitivity. Biochim Biophys Acta 2012;1820:2062-71.

[11] Hertzberg RP, Caranfa MJ, Hecht SM. On the mechanism of topoisomerase I inhibition by camptothecin: evidence for binding to an enzyme-DNA complex. Biochemistry 1989;28:4629-38.

[12] Staker BL, Hjerrild K, Feese MD, Behnke CA, Burgin Jr AB, Stewart L. The mechanism of topoisomerase I poisoning by a camptothecin analog. Proc Natl Acad Sci USA 2002;99:15387-92.

[13] Luzzio MJ, Besterman JM, Emerson DL, Evans MG, Lackey K, Leitner PL, et al. Synthesis and antitumor activity of novel water soluble derivatives of camptothecin as specific inhibitors of topoisomerase I.J Med Chem 1995;38:395-401.

[14] Antony S, Agama KK, Miao ZH, Hollingshead M, Holbeck SL, Wright MH, et al. Bisindenoisoquinoline bis-1,3-\{(5,6-dihydro-5,11-diketo-11H-indeno[1,2c]isoquinoline)-6-propylamino\}propane bis(trifluoroacetate) (NSC 727357), a DNA intercalator and topoisomerase inhibitor with antitumor activity. Mol Pharmacol 2006;70:1109-20.

[15] Teicher AB. Next generation topoisomerase I inhibitors: rationale and biomarker strategies. Biochem Pharmacol 2008;75:1262-71.

[16] Lee MP, Brown SD, Chen A, Hsieh TS. DNA topoisomerase I is essential in Drosophila melanogaster. Proc Natl Acad Sci USA 1993;90:6656-60.

[17] Balaña-Fouce R, Garcia-Estrada C, Perez-Pertejo Y, Reguera RM. Gene disruption of the DNA topoisomerase IB small subunit induces a non-viable phenotype in the hemoflagellate Leishmania major. BMC Microbiol 2008;8:113.

[18] Bakshi RP, Shapiro TA. RNA interference of Trypanosoma brucei topoisomerase IB: both subunits are essential. Mol Biochem Parasitol 2004;136:249-55.

[19] Reguera RM, Redondo CM, Gutierrez de Prado R, Pérez-Pertejo Y, Balaña-Fouce R. DNA topoisomerase I from parasitic protozoa: a potential target for chemotherapy. Biochim Biophys Acta 2006;1759:117-31. 
[20] Balaña-Fouce R, Prada CF, Requena JM, Cushman M, Pommier Y, ÁlvarezVelilla R, et al. Indotecan (LMP400) and AM13-55: two novel indenoisoquinolines show potential for treating visceral leishmaniasis. Antimicrob Agents Chemother 2012;56:5264-70.

[21] Shu X, Royant A, Lin MZ, Aguilera TA, Lev-Ram V, Steinbach PA, et al. Mammalian expression of infrared fluorescent proteins engineered from a bacterial phytochrome. Science 2009;324:804-7.

[22] Osorio Y, Travi BL, Rensio AR, Peniche AG, Melby PC. Identification of small molecule lead compounds for visceral leishmaniasis using novel ex vivo splenic explant model system. Plos Negl Trop Dis 2011;5:e962.

[23] Dexheimer TS, Pommier Y. DNA cleavage assay for the identification of topoisomerase I inhibitors. Nat Protoc 2008;3:1736-49.

[24] Tanizawa A, Fujimori A, Fujimori Y, Pommier Y. Comparison of topoisomerase I inhibition, DNA damage, and cytotoxicity of camptothecin derivatives presently in clinical trials. J Natl Cancer Inst 1994;86:836-42.

[25] Valenti M, Nieves-Neira W, Kohlhagen G, Kohn KW, Wall ME, Wani MC, et al. Novel 7-alkyl methylenedioxy-camptothecin derivatives exhibit increased cytotoxicity and induce persistent cleavable complexes both with purified mammalian topoisomerase I and in human colon carcinoma SW620 cells. Mol Pharmacol 1997;52:82-7.

[26] Coombs GH, Hart DT, Capaldo J. Leishmania mexicana: drug sensitivities of promastigotes and transforming amastigotes. J Antimicrob Chemother 1983;11:151-62.

[27] Dallavalle S, Delsoldato T, Ferrari A, Merlini L, Penco S, Carenini N, et al. Novel 7-substituted camptothecins with potent antitumor activity. J Med Chem 2000;43:3963-9.

[28] Zhu AX, Ready N, Clark JW, Safran H, Amato A, Salem N, et al. Phase I and pharmacokinetic study of gimatecan given orally once a week for 3 of 4 weeks in patients with advanced solid tumors. Clin Cancer Res 2009;15: 374-81.

[29] Burke TG, Munshi CB, Mi Z, Jiang Y. The important role of albumin in determining the relative human blood stabilities of the camptothecin anticancer drugs. J Pharm Sci 1995;84:518-9.

[30] Dorlo TP, van Thiel PP, Huitema AD, Keizer RJ, de Vries HJ, Beijnen JH, et al. Pharmacokinetics of miltefosine in Old World cutaneous leishmaniasis patients. Antimicrob Agents Chemother 2008;52:2855-60. 